\title{
The Role of Local Community in the Marketing Planning for Sustainable Tourism National Park Skadar Lake (Montenegro)
}

\author{
Darko Lacmanović, Iva Bulatović* \\ Received: February 2014 | Accepted: August 2014
}

\begin{abstract}
The relationship between local community and tourism sector is an important issue in the marketing management of tourist destinations in theoretical and practical terms.

It is especially important to consider specific issues relating to sustainable tourism marketing process and the participation of local people in the process. The subject of this work is to determine the existence of significant differences in the local community attachment and involment that may affect the marketing plan in offering different types of sustainable tourism in the National Park "Skadar Lake".

The research was conducted using a survey on a sample of 51 households in the stated area, using few statistical method for processing data (The T-test for independent samples; ANOVA).

Examined: the perceived importance of the supply of sustainable forms of tourism; attitude towards tourists / visitors and the perception level of tourism marketing trends.

Testing the validity of the hypotheses noted the following.

Rejection of Hypothesis 1 clearly states that men and women do not have clear differences of opinions regarding the development of sustainable tourism offers.

Partially confirmed Hypothesis 2 showed a more significant difference in the positive attitudes of the middle-aged group, which indicates the need for careful marketing communication in relation to other age groups.

Confirming the Hypothesis 3 has highlighted the clearer perception of local residents who are employed in the tourism sector about the advantages and disadvantages of tourism development.

The Hypothesis 4 regarding significant monitoring of the developments in the tourism market of highly educated residents and resident-employees in the tourism sector, public services, culture and education in relation to other comparable groups has been confirmed.
\end{abstract}

\footnotetext{
* University Mediterranean - Podgorica, Faculty for Tourism MTS Montenegro Tourism School - Bar; Maršala Tita bb,
} 85000 Bar, Montenegro, Corresponding author: darko.lacmanovic@unimediteran.net 
The rejection of the Hypothesis 5 shows that the place of residence does not significantly affect the views of local residents about the development of sustainable tourism offers.

Marketing planning the sustainable tourism have to be based on the desired relation to meeting the needs of tourism consumers and meeting the basic interests of the local population in protected areas.

The key issue is to find an institutional approach in the community that ensures more comprehensive marketing plan.

Key words: destination marketing management, sustainable tourism, marketing planning

\section{Introduction}

The relationship between local community and tourism sector is an important issue in the marketing management of tourist destinations in theoretical and practical terms. Numerous studies have been focused on the examination of the attitudes of the local population in relation to different aspects of the development and marketing of a tourist destination (Uriely, Israeli and Reichel, 20O3; Inbakaran, Jackson, 2OO5; Woosnam, Norman, 2OIO; Nunkoo, Gursoy, 2OI2; Lee, 2OI3; Job, Paesler, 2OI3).

It is especially important to consider specific issues relating to the marketing of sustainable tourism and the participation of local people in the process.

The subject of this work is to determine the existence of significant differences in the local community attachment and involment that may affect the marketing plan in offering different types of sustainable tourism in the National Park "Skadar Lake".

The research was conducted using a survey on a sample of 5 I households in the stated area, using the system of closed questions, mostly with Likert scale in collecting data and few statistical method was used for processing data (The T-test for independent samples; ANOVA).

Examined: the perceived importance of the supply of sustainable forms of tourism; attitude towards tourists / visitors and the perception level of tourism marketing trends.

Discussing the results of the research, it has been made several observation of importance to marketing planning of the offers of sustainable tourism in areas such as the National Park "Skadar Lake", especially in terms of situation analysis, marketing strategies, marketing mix activities and the control of marketing plan.

\section{Literature Review}

Early observations on the relationship of the local population and the effects of tourism development are discussed as a theoretical template in the following studies and point out the negative impact of tourism development through tourism capacity overload due to the large number of tourists (Doxy, I975; Buttler, I980, in: Uriely, Israeli and Reichel , 2003;).

Key settings were developed through the Social Exchange Theory (SET) which indicates the attitude of the local population in relation to the object of tourism development in terms of positive and negative effects, which means that the choice of an individual is based on his estimate of the expected costs and benefits of a given process (Blay I964; Homans, I967; in: Uriely, Israeli and Reichel, 2003; Harrill 2004; in: Woosnam, Norman, 2OIO; Skidmore I975, in: Nunkoo, Gursoy, 2OI2). 
In response to the Social Exchange Theory (SET), in discussing the relations between local residents and tourism, the theory of social representations was used that explains the creation and distribution of social knowledge between different groups, societies and communities although tourists are not considered to be part of such social groups (Pearce, Moscardo , and Ross, I996; in: Wosnam, Norman, 20IO).

Applying Durhheim's theory in the context of tourism, further elaborates the view that if local residents and tourists share the beliefs and behaviors and have mutual interactions will then appear that there is an emotional solidarity between these two different social groups (Durkheim ([I9I5] I995; in: Wosnam, Norman, 2OIO).

Further consideration of the connection between the attitudes and behavior of local people in relation to tourism was formulated through the theory of identity, which explains the choice and decision-making of individuals within specific social structure of the local community. Identity theory provides an important link between the individual and the larger social structures as a concept that is missing in the theory of attitudes (SET) (Stets, Biga, 2003 in: Nunkoo, Gursoy, 20I2). Studies indicate that although the identity of an individual affects his behavior, such effects are independent of the influence of attitudes on behavior (Biddle et al, I987; Hagger et al., 2007; in: Nunkoo, Gursoy, 2OI2). It is believed that the theory of identity is a more general theory compared to the theory of attitudes, considering that it can explain a wide range of behaviors in certain situations, including support for tourism by local people (Nunkoo, Gursoy, 2OI2).

Further development of the research indicates that there is no universal position on the impact of tourism on the local population, but it is in direct dependence on a number of factors, such as the nature of tourist activities, type of the local community and the level of difference between the various population groups within the local community (Haralambopoulos and Pizam, I996; in: Uriely, Israeli and Reichel 2003;).

In addition, the studied factors were: the level of economic development, socio-demographic characteristics, economic dependence on tourism, the extent of interaction of local residents and tourists, the spatial distance from the tourist attractions, length of stay and devotion to the traditional culture of the local area. A demographic profile of people with positive attitudes toward tourism was formed: women, employed, higher income levels, higher education levels, higher political position in society, the place of living in an urban environment. Work in economic activities dependent on tourism leads to a strong positive attitude towards tourism but also the rapid identification of negative impacts that lead to a negative attitude (Inbakaran, Jackson, 2005).

The same authors have carried out a summary of previous findings related to various groups of local residents on the positive ("Lovers," "Enthusiasts" or "Supporters"), negative ("Haters," "Somewhat irritated," "Opponents," or "Cynics".) or neutral attitude ("In-betweeners," "Middle of the roaders", "Neutrals" and "Taxpayers") to tourism, as shown in the Table I.

With the advent of the paradigm of sustainable development possibilites of coexistence of tourism development and the quality of the environment are noticed more strongly, particularly through the concept of community-based tourism development that aims to generate income and minimize poverty through the involvement of local population using indigenous resources (Sebele, 2OIO; Taylor, I995; in: Lee, 2OI3; Palm, Pye, 2OOI; in. Job, Paesler, 2OI3). Understanding the support of the local population for the concept of sustainable tourism development is a critical factor in the successful management and marketing of community-based tourism. Supporting the development of sustainable tourism as related to nature- 
Table 1. Summary of research through cluster analysis of attitudes of local residents

\begin{tabular}{|l|l|}
\hline Study & Cluster name (\%) \\
\hline $\begin{array}{l}\text { Davis, D., Allen, J. and Cosenza, A. 1988. Segmenting Local Resi- } \\
\text { dents by Their Attitudes, Interests, and Opinions Toward Tourism. } \\
\text { Journal of Travel Research, 27(2), 2-8. }\end{array}$ & $\begin{array}{l}\text { Lovers (20); Haters (16); Cautious romantics (21); } \\
\text { In-betweeners (18); Love 'em for a reason (26) }\end{array}$ \\
\hline $\begin{array}{l}\text { Ryan, C. and Montgomery, D. 1994. The Attitudes of Bakewell } \\
\text { Residents to Tourism and Issues in Community Responsive Tour- } \\
\text { ism. Tourism Management, 15(6), 358-69. }\end{array}$ & $\begin{array}{l}\text { Enthusiastics (22); Middle of the roaders (54); } \\
\text { Somewhat irritated (24); }\end{array}$ \\
\hline $\begin{array}{l}\text { Madrigal, R. 1995. Residents' Perceptions and the Role of Govern- } \\
\text { ment. Annals of Tourism Research, 22(1), 86-102. }\end{array}$ & Lovers (13); Realists (56); Haters (31) \\
\hline $\begin{array}{l}\text { Fredline, E. and Faulkner, B. 2000. Host Community Reactions: A } \\
\text { Cluster Analysis. Annals of Tourism Research, 27(3), 763-84. }\end{array}$ & $\begin{array}{l}\text { Lovers (23); Haters (15); Ambivalent supporters } \\
\text { (29); Realists (24); Concerned for a reason (9) }\end{array}$ \\
\hline $\begin{array}{l}\text { Weaver, D. and Lawton, L. 2001. Resident Perceptions in the Ur- } \\
\text { ban-Rural Fringe. Annals of Tourism Research, 28(2), 439-58. }\end{array}$ & Supporters (27); Neutrals (51); Opponents (22) \\
\hline $\begin{array}{l}\text { Williams, J. and Lawson, R. 2001. Community Issues and Resident } \\
\text { Opinions of Tourism. Annals of Tourism Research, 28(2), 269-90. }\end{array}$ & $\begin{array}{l}\text { Lovers (44); Cynics (10); Taxpayers (25); Inno- } \\
\text { cents (20) }\end{array}$ \\
\hline
\end{tabular}

Source: Inbakaran, R. and Jackson, R. 2005.

based tourism, ecotourism, rural tourism and heritage tourism has been studied in Western nations, but remains an intense debate in Eastern nations (Gursoy et al., 2009; Lai, Nepal, 2006; Nicholas et al., 2009; Tosun, 2006; in: Lee, 2OI3).

Community attachment of local residents and the level of support for tourism development in terms of the existence of significant links has been researched by several studies (McCool \& Martin, I994; Pennington-Gray, 2005; Nicholas et al., 2009; in: Lee, 2OI3). Involvement of local communities in the decision-making about sustainable development of community-based tourism by reducing the negative and increasing the positive effects as evidenced by the level of participation and the distribution of decision-power, is the subject of several studies (Arnstein (I969; Jamal, Getz, I995; Okazaki, 2008; Selin, Chavez, I995; in: Lee, 20I3).

Religious identity and the attitude of local communities towards cultural heritage tourism on the case of Nazareth have been studied by Uriely, N., Israeli, A. and Reichel, A. who came to the conclusion that a group of people of a particular religious background provides little support for religious events of other religious backgrounds despite the expected economic benefits; that residents of a heritage tourism destination whose cultural or religious heritage is positively presented and promoted are more likely to support tourism development compared to those residents whose cultural heritage is ignored; and that the attitudes of local residents towards tourism development may be formed on the basis of non-economic losses, such as proximity to heritage (Uriely, Israeli and Reichel, 2003).

R.Inbakaran and R.Jackson formed several clusters of local residents using several profile characteristics such as demographic, location, economic, and found the following (Inbakaran, Jackson, 2005):

- There is a significant negative correlation between positive attitudes and residence: residents who live away from the main tourist attractions have a more positive attitude regarding tourism.

- Residents who are more involved in tourism activity perceive advantages and disadvantages of tourism more clearly

- There is a significant correlation between negative attitudes and: level of education, length of stay and employment in tourism (the higher the education level, the position 
is less negative; the longer the stay, the less negative attitudes about tourism development).

Using a specific local community on the island of Mauritius, R.Nunkoo and D.Gursoy, tested the theory of identity and came to several conclusions (Nunkoo, Gursoy, 2OI2):

a) Residents with a high level of identity in employment see tourism impact as negative and provide less support for tourism, which suggests that local planners should develop tourism in a way that does not disturb the island's identity in employment

b) Residents with higher environmental identity (ecocentric attitudes) are likely to be less supportive of tourism development, which suggests that local planners must be very sensitive about environmental influences on development.

c) Residents who express feminine characteristics are much more likely to see the negative impact of tourism and be less supportive of tourism activity, which suggests that planners should understand that gender is a complex variable and an understanding of how male and female residents react to tourism development can provide limited information for the purpose of planning.

The above conclusions apply to small communities in the lower level of economic development and the specific conditions of relative isolation.

Examining the significance model of the impact of community attachment and community involvement of local residents on the perception of costs and benefits of sustainable tourism development, T.H.Lee, formulates several important conclusions and suggestions (Lee, 20I3). Perceived benefits and costs affect the support for the sustainable development of tourism, and the behavior model of local residents reflects the international and multicultural perspective of community-based sustainable tourism development. Support for sustainable tourism is based more on the perceived benefits than perceived costs.

Community attachment and community involvement significantly - positively and directly - correlated with the expected benefits and indirectly and positively correlated with the support for the sustainable development of tourism, which is why these variables can be effectively used to estimate the above support.

No significant links of community attachment and community involvement in relation to the perceived costs have been found, which means that the those variables are not efficient predictors of the perceived costs of sustainable tourism.

Promotion of community-based festivals and events, for example, can increase the level of community attachment of local residents, which will cause an increase in the level of the perceived benefits and support the development of sustainable tourism. Programs designed to protect the environment and improve the standard of living will increase the dependency of the residents of the local community and its resources, which will be expressed through a high level of perceived benefit and support for the development of sustainable tourism.

The results of this study encourage the implementation of community-based programs and/or activities that strengthen the emotional attachment between people and their communities.

Promotional programs should emphasize community involvement which can lead to increased involvement of the local people in the decision-making process related to sustainable tourism as a critical point in support of this type of development (Lee, 2OI3). 


\section{Hypotheses}

In accordance with literature review and aims of this work, the following hypotheses are suggested:

Hypothesis I: Women have a more positive attitude towards tourism development than men have.

Hypothesis 2: The middle-aged residents have a more positive attitude towards the development of tourism than youth and seniors.

Hypothesis 3: The residents employed in the tourism sector have a less negative attitude towards tourists / visitors.

Hypothesis 4: Highly educated residents are more involved in tourism development and better informed about tourist trends, as well as residents employed in the tourism sector, public services, culture and education.

Hypothesis 5: Residents who live away from the main tourist sites have more positive attitude towards tourism.

\section{Methods and Data}

\section{Methods}

For the purpose of this paper, several scientific methods were used. The Poll was used for collecting data and a few statistical method was used for processing data (The T-test for independent samples; ANOVA). T-test for independent samples is used for comparison of mean values of results and definition of statistical significance of their differences. Independent samples are samples that do not have any correlation after the measurement.

T-test of independent samples has been applied with the purpose of comparing arithmetical means of the two groups - male and female respondents.

One-way analysis of variance ANOVA was used to define if there is statistically significant correlation between dependent variables (questions) and independent variable (Respondents' profile: Sex, Age, Education, Status, Employment sector). For measuring differences between attitudes, authors have used Eta square. Using formula: sum squares/total we will get the value of eta square

It must be noted when significance - $\mathrm{p}<\mathrm{O} .05$ here is a significant difference between the mean values of the dependent variables in each group. Otherwise, when the $\mathrm{p}>0.05$ the difference between the two groups is not significant, but coincidental. On the other hand,for measuring differences between attitudes authors have used Eta square. Using formula: $\mathrm{t}^{2} /$ $t^{2}+(\mathrm{NI}+\mathrm{N} 2-2)$ we will get the value of eta square. ( $t$ - result of T-test, NI-number of male respodents, $\mathrm{N}_{2}$ - number of female respodents. Eta square value will be given in the special column. (the value of eta square: O.OI - small effect; O.O6 - medium effect; O.I4 - large effect).

\section{Sample}

Special, closed questionnaire was designed. The questionnaire included I8 questions and 5I people answered it, which is considered as a valid sample. According to the census of Montenegro from the 2OIIth, in the area of Skadar Lake (The municipalities of Podgorica, Bar and Cetinje) live 244642 inhabitants or $39.46 \%$ of the total population of Montenegro. A statisti- 
cally representative sample of the total population of Montenegro is Ioo participants, so the adequate sample for this survey is 39 residents. Examined sites were Bar, Dodoši, Godinje, Karuč, Murići, Ostros, Podgorica, Plavnica, Crnojevića River, Sutomore Virpazar Vranjina. The following table presents more details about the sample.

Table 2. Respondents' profile

\begin{tabular}{|c|c|c|c|c|c|}
\hline \multirow{3}{*}{ Sex (frequency) } & male & 31 & \multirow{3}{*}{ Age (\%) } & \multicolumn{2}{|c|}{ 18-35: 42} \\
\hline & female & 20 & & \multicolumn{2}{|c|}{$36-55: 34$} \\
\hline & Total & 51 & & \multicolumn{2}{|c|}{$56-: 24$} \\
\hline \multirow{4}{*}{ Education (\%) } & Secondary school & 35.3 & \multirow{4}{*}{ Status (\%) } & employed & 66.7 \\
\hline & College & 9.8 & & unemployed & 19.6 \\
\hline & Faculty/Academy & 45.1 & & Retiree & 9.8 \\
\hline & Others & 9.8 & & Others & 3.9 \\
\hline \multirow{4}{*}{ Employment sector (\%) } & Tourism and hospitality & 31.4 & Industry & & 3.9 \\
\hline & Agriculture & 9.8 & Education/healthcare & & 11.8 \\
\hline & Commerce & 3.9 & Culture & & 2 \\
\hline & Public services & 9.8 & Science & & 2 \\
\hline
\end{tabular}

Most of respondents who are employed in the tourism and hospitality sector work in restaurants and travel agencies. Three respondents work in the hotel, but twelve respondents gave an answer they do something else. (Administration, ticketing agent, tour guide, IT, Sales).

Most respondents work in the private sector. More than $58 \%$ of respondents work in the private sector, I9.6\% work in the public sector and 2I.6\% of respondents didn't answer. More than $47 \%$ of respondents generate income completely / mostly and partly from tourism, while $52.9 \%$ of respondents don't.

\section{Research results}

One of the survey's questions was "evaluate satisfaction with the development of some types of tourism in the Skadar Lake Zone using a scale from I (dissatisfied) to IO (very much satisfied)."

The T-test for independent samples is used to determine whether there is a statistically significant difference between the attitudes of female respondents and male respondents.

Look at column p. In our case, a significant difference between the average grades of (dis) satisfaction with the development of certain forms of tourism in the area of Skadar Lake is only noticeable in case of excursions (O.042). It means women (mean: 5.9) have significantly more positive attitude towards to the development of this type of tourism than a men (mean: 4.7).

Analyzing all other dependent variables in regard to the respondents' gender, we can conclude there are significant differences between attitudes towards tourism development. However, these findings are not sufficient to reject the Hypotheses I i.e. it is necessary to measure the impact of gender differences. It means to determine gap between two groups in order to find out if differences are coincidental or not.

According to these parameters, we can conclude there are not major differences between male and female attitudes toward tourism development. 
Table 3. Test of Hypothesis 1

\begin{tabular}{|c|c|c|c|c|c|c|}
\hline \multirow[b]{2}{*}{ Dependent variables } & \multicolumn{2}{|c|}{ Mean } & \multicolumn{3}{|c|}{ T-test for Equality of Means } & \multirow{2}{*}{ Eta square } \\
\hline & Male & Female & $\mathrm{t}$ & $\mathrm{N} 1+\mathrm{N} 2-2$ & $\mathrm{P}$ & \\
\hline Excursions & 4.73 & 5.95 & -2.09 & 48 & 0.04 & 0.08 \\
\hline Events & 4.23 & 4.20 & 0.03 & 49 & 0.97 & 0.05 \\
\hline Sports fishing & 4.58 & 4.70 & -0.14 & 49 & 0.88 & 0.0004 \\
\hline Wine tours & 3.93 & 3.65 & 0.43 & 48 & 0.66 & 0.0038 \\
\hline Hike \& Bike & 3.60 & 4.05 & -0.63 & 48 & 0.52 & 0.0084 \\
\hline Lake Cruise & 5.87 & 6.35 & -0.79 & 49 & 0.43 & 0.01 \\
\hline Cultural sightseeing & 4.39 & 4.90 & -0.71 & 49 & 0.47 & 0.01 \\
\hline Ecotourism & 2.97 & 3.37 & -0.64 & 48 & 0.52 & 0.0085 \\
\hline Agro tourism & 2.97 & 2.80 & 0.28 & 49 & 0.77 & 0.0016 \\
\hline Bird watching & 4.74 & 5.50 & -1.07 & 49 & 0.28 & 0.02 \\
\hline
\end{tabular}

Despite the fact that women rated their satisfaction more positive than men, the previous analysis showes that the differences were insignificant, and therefore Hypothesis I can not be verified.

Hypothesis I: Women have a more positive attitude towards tourism development than men have. FALSE. There is not significant deference between male and female attitudes towards tourism development.

Calculating the mean values of opinion ratings between 3 different age groups of the population of different ages ( $\mathrm{I}$ - young residents from I8 to 35 years, 2 - middle aged residents from 36 to 55 years and 3 - Senior citizens, over 55) we conclude that middle-aged residents

Table 4. Test of Hypothesis 2

\begin{tabular}{|c|c|c|c|c|c|c|}
\hline \multicolumn{2}{|c|}{ Dependent variables } & Excursions & Events & Sports fishing & Wine tours & Hike \& Bike \\
\hline \multirow[t]{2}{*}{1.00} & Mean & 5.15 & 3.95 & 4.25 & 3.40 & 3.45 \\
\hline & Std. Deviation & 1.663 & 2.543 & 2.613 & 2.370 & 2.543 \\
\hline \multirow[t]{2}{*}{2.00} & Mean & 5.47 & 5.00 & 5.23 & 4.43 & 4.75 \\
\hline & Std. Deviation & 2.695 & 2.872 & 2.926 & 2.448 & 2.792 \\
\hline \multirow[t]{2}{*}{3.00} & Mean & 5.45 & 4.00 & 4.91 & 4.00 & 3.33 \\
\hline & Std. Deviation & 1.634 & 2.000 & 2.874 & 1.858 & 1.370 \\
\hline \multirow[t]{2}{*}{ Total } & Mean & 5.33 & 4.32 & 4.75 & 3.89 & 3.85 \\
\hline & Std. Deviation & 2.045 & 2.544 & 2.765 & 2.280 & 2.440 \\
\hline \multicolumn{2}{|c|}{ Dependent variables } & Lake cruise & Cultural sightseeing & Ecotourism & Agro tourism & Bird watching \\
\hline \multirow[t]{2}{*}{1.00} & Mean & 5.55 & 4.15 & 2.78 & 2.55 & 5.00 \\
\hline & Std. Deviation & 1.932 & 2.134 & 1.750 & 1.877 & 2.533 \\
\hline \multirow[t]{2}{*}{2.00} & Mean & 7.11 & 5.88 & 3.88 & 3.82 & 5.76 \\
\hline & Std. Deviation & 2.260 & 2.869 & 2.825 & 2.377 & 2.773 \\
\hline \multirow[t]{2}{*}{3.00} & Mean & 5.58 & 3.58 & 2.50 & 2.16 & 4.08 \\
\hline & Std. Deviation & 1.831 & 1.781 & 1.243 & 1.193 & 1.831 \\
\hline \multirow[t]{2}{*}{ Total } & Mean & 6.10 & 4.61 & 3.10 & 2.89 & 5.04 \\
\hline & Std. Deviation & 2.123 & 2.490 & 2.146 & 2.023 & 2.507 \\
\hline
\end{tabular}


have a more positive attitude towards tourism development in destination compared to the other two age groups (Table 4.)

The next question is: "Is observed difference statistically significant?" ANOVA is used as a method for determining exactly what kind of differences is present. Look at the next table. The most important column is $\mathrm{p}$ the difference between the average values of the dependent variable is statistically significant in cases where the $\mathrm{p}<0.05$. The difference between attitudes towards tourism development of three age groups is evident i.e. Lake cruise $(p=0.048)$, cultural tourism ( $p=0.02 \mathrm{I}$ ) and rural tourism ( $\mathrm{p}=\mathrm{O} .054)$. In these cases, middle - aged population of National Park Skadar Lake has more positive attitude towards tourism development. In other cases, there is no statistically significant difference between their attitudes.

Table 5. Test of Hypothesis 2, ANOVA and Eta Square

\begin{tabular}{|c|c|c|c|c|}
\hline \multicolumn{5}{|c|}{ ANOVA } \\
\hline \multicolumn{2}{|l|}{ Dependent variables } & Sum of Squares & $p$ & Eta Square \\
\hline \multirow{2}{*}{ Excursions } & Between Groups & 1.154 & 0.876 & 0.005 \\
\hline & Total & 196.667 & & \\
\hline \multirow{2}{*}{ Events } & Between Groups & 11.826 & 0.410 & 0.038 \\
\hline & Total & 310.77 & & \\
\hline \multirow{2}{*}{ Sports fishing } & Between Groups & 9.336 & 0.553 & 0.025 \\
\hline & Total & 367.06 & & \\
\hline \multirow{2}{*}{ Wine tours } & Between Groups & 9.742 & 0.401 & 0.039 \\
\hline & Total & 244.47 & & \\
\hline \multirow{2}{*}{ Hike \&Bike } & Between Groups & 19.363 & 0.199 & 0.069 \\
\hline & Total & 279.97 & & \\
\hline \multirow{2}{*}{ Lake cruise } & Between Groups & 26.858 & 0.048 & 0.124 \\
\hline & Total & 216.49 & & \\
\hline \multirow{2}{*}{ Cultural sightseeing } & Between Groups & 44.401 & 0.024 & 0.149 \\
\hline & Total & 297.63 & & \\
\hline \multirow{2}{*}{ Ecotourism } & Between Groups & 16.557 & 0.167 & 0.076 \\
\hline & Total & 216.47 & & \\
\hline \multirow{2}{*}{ Rural tourism } & Between Groups & 23.403 & 0.054 & 0.119 \\
\hline & Total & 196.49 & & \\
\hline \multirow{2}{*}{ Bird watching } & Between Groups & 19.943 & 0.208 & 0.066 \\
\hline & Total & 301.91 & & \\
\hline
\end{tabular}

Note: $p<0.05$

It is obviously that effect size depends on variables. Only in case of excursions, there is not significant effect size. It means there is no difference between age groups ' attitudes towards tourism development.

Although ANOVA doesn't show statistical significant difference between young, middle aged people and seniors, means and eta squares are disabling rejections of Hypothesis 2 at all. Actually, differences of opinions exist and middle-aged respondents have more positive attitude towards tourism development. It is enough for accepting Hypothesis 2. 
Hypothesis 2: The middle-aged residents have a more positive attitude towards the development of tourism than youth and seniors. TRUE

On the other hand, we asked respondents to rate the level of agreement with the premises presented in the table below (I - disagree, 2- slightly agree, 3 moderately agree, 4-agree a lot, 5-absolutely agree). Mean values are presented, too.

Table 6. Test of Hypothesis 3

\begin{tabular}{|l|l|r|r|}
\hline \multicolumn{2}{|c|}{ Sector (independent variable) } & $\begin{array}{c}\text { Premise: I am happy when } \\
\text { tourists arrive because I meet } \\
\text { new manners and cultures } \\
\text { (dependent variable) }\end{array}$ & $\begin{array}{c}\text { Premise: I am not happy when tourists } \\
\text { arrive, but I understand benefits of their } \\
\text { visits and stays for the economy of the } \\
\text { Skadar Lake Zone. (dependent variable) }\end{array}$ \\
\hline $\begin{array}{l}\text { Tourism, hospitality } \\
\text { and public services }\end{array}$ & Mean & 4.66 & 1.71 \\
\cline { 2 - 5 } Agriculture & Std. Deviation & 0.483 & 1.101 \\
\hline \multirow{3}{*}{ Industry } & Mean & 3.40 & 3.40 \\
\cline { 2 - 5 } & Std. Deviation & 1.516 & 1.816 \\
\hline \multirow{2}{*}{ Education, culture } & Mean & 4.00 & 3.00 \\
\cline { 2 - 5 } & Std. Deviation & 1.414 & 2.828 \\
\cline { 2 - 5 } & Mean & 3.90 & 2.50 \\
\hline \multirow{2}{*}{ Total } & St. Deviation & 0.994 & 1.433 \\
\cline { 2 - 5 } & Std. Deviation & 4.26 & 2.21 \\
\hline
\end{tabular}

We can conlude that citizens of National Park Skadar Lake who work in tourism and hospitality sector have more positive attitude towards tourists and their visits than others who work in sector of industry, education, agroculture. ANOVA showes that significat diference between means of dependent variables exist within these four examined groups. (p $\leq$ 0.05).

Table 7. Test of Hypothesis 3 ANOVA and Eta Square

\begin{tabular}{|c|c|c|c|c|}
\hline \multicolumn{4}{|c|}{ ANOVA } & \multirow{2}{*}{ Eta square } \\
\hline \multicolumn{2}{|l|}{ Dependent variable } & Sum of Squares & $P$ & \\
\hline \multirow{2}{*}{$\begin{array}{l}\text { Premise: I am happy when tourists } \\
\text { arrive because I meet new manners and } \\
\text { cultures }\end{array}$} & Between Groups & 8.60 & 0.016 & 0.25 \\
\hline & Total & 33.36 & & \\
\hline \multirow{2}{*}{$\begin{array}{l}\text { Premise: I am not happy when tourists } \\
\text { arrive, but I understand benefits of their } \\
\text { visits and stays for the economy of the } \\
\text { Skadar Lake Zone. }\end{array}$} & Between Groups & 14.33 & 0.053 & 0.18 \\
\hline & Total & 78.31 & & \\
\hline
\end{tabular}

Eta square showes that the major effect size is present. It showes independent variable's impact on dependent variable. These results are enough for accepting hypothesis 3 .

Hypothesis 3: The residents employed in the tourism sector have a less negative attitude towards tourists / visitors. TRUE.

Respondents also have task to evaluate the degree of their agreement with the premise: 
I follow developments on the tourist market; I know what is modern and what tourists seek for. It is used the same evaluation scale as in previous case. Their responses were different depending on the level of education and activity sector. Calculating the mean, ANOVA and Eta square we can conclude that Hypothesis 4 is partly true. Actually, highly educated residents have expressed higher level of agreement with the set premise ( mean: 4.04 $\mathrm{p}=0.017$, eta square: O.I72), which means that they are more involved in tourism development and they are up to date with the latest tourist trends.

Table 8. Test of Hypothesis 4

\begin{tabular}{|l|r|r|r|r|}
\hline \multicolumn{5}{|c|}{ I follow developments on the tourist market, I know what is modern and what tourists seek for } \\
\hline Education (independent variable - groups) & \multicolumn{1}{|c|}{ Mean } & Std. Deviation & \multicolumn{1}{c|}{ ANOVA p } & \multicolumn{1}{c|}{ Eta square } \\
\hline Secondary school & 2.88 & 1.529 & 0.017 & 0.172 \\
\hline College & 3.00 & 1.224 & & \\
\hline Faculty/Academy & 4.04 & 1.06508 & & \\
\hline Total & 3.47 & 1.37823 & & \\
\hline
\end{tabular}

On the other hand, the next table confirms hypothesis that people who work in tourism and hospitality sector and public services sector are more involved in tourism industry and they are more up to date with the latest tourists' trends than others are. ( mean: 4.04, $\mathrm{p}=0.054$, eta square:O.194)

Table 9.Test of Hypothesis 4

\begin{tabular}{|l|r|r|r|r|}
\hline \multicolumn{5}{|c|}{ I follow developments on the tourist market; I know what is modern and what tourists seek for } \\
\hline Activity sector (independent variable -groups) & \multicolumn{1}{|c|}{ Mean } & Std. Deviation & ANOVA P & Eta square \\
\hline Tourism, hospitality and public services & 4.04 & 1.203 & 0.054 & 0.194 \\
\hline Agriculture & 3.00 & 1.414 & & \\
\hline Industry & 2.00 & 1.414 & & \\
\hline Education and culture & 3.20 & 1.229 & & \\
\hline Total & 3.57 & 1.328 & & \\
\hline
\end{tabular}

This is enough for acceptance of Hypothesis 4.

Hypothesis 4: Highly educated residents are more involved in tourism development and better informed about tourist trends, as well as residents employed in the tourism sector, public services, culture and education. TRUE.

Attitudes of two groups have been examined in order to prove Hypothesis 5. The first group includes people who live in tourist place on the area of Skadar Lake ( Vranjina, Virpazar, Murići, Rijeka Crnojevića, Bar, Sutomore, Podgorica, Plavnica), while the second group includes people who don't live in tourist place. In this case, we have two independent groups and we have used T-test for determination of statistical significance. Dependent variables, results of T-test and eta square are presented in the table IO.

There is no significant statistical difference between examined groups and there is no significant effect size (Look at $\mathrm{p}$ and Eta square). These test's results are enough for rejecting Hypothesis 5. It means there is not significant relation between residents' attitudes and their place of living. 
Table 10. Test of Hypothesis 5

\begin{tabular}{|c|c|c|c|c|}
\hline \multicolumn{5}{|c|}{ Independent Samples Test } \\
\hline & \multicolumn{4}{|c|}{ t-test for Equality of Means } \\
\hline & $\mathrm{t}$ & $d f$ & $\mathrm{P}$ & Eta Square \\
\hline $\begin{array}{l}\text { Premise: I am happy when tourists arrive because I meet } \\
\text { new manners and cultures }\end{array}$ & -0.563 & 49 & 0.576 & 0.006 \\
\hline $\begin{array}{l}\text { Premise: I am not happy when tourists arrive, but I } \\
\text { understand benefits of their visits and stays for the } \\
\text { economy of the Skadar Lake Zone. }\end{array}$ & -0.325 & 49 & 0.746 & 0.002 \\
\hline
\end{tabular}

Hypothesis 5: Residents who live away from the main tourist sites have more positive attitude towards tourism. FALSE.

\section{Discussion and Conclusion}

Marketing planning of forms of sustainable tourism of the NP "Skadar Lake" area can be reliably made only on the basis of a balanced approach between the stated attitudes of selected groups of the local population and the requirements of particular market segments. The existence of possibly significant differences in the attitudes of certain groups of local residents about the impact and development of sustainable tourism offers is assumed by the relevant hypotheses.

Testing the validity of the hypotheses noted the following.

Rejection of Hypothesis I clearly states that men and women do not have clear differences of opinions regarding the development of sustainable tourism offers which is not in line with the findings of a survey which identified a more pronounced negative attitude towards the impact of tourism by female residents (Nunkoo, Gursoy, 2OI2) but in terms of the specific behavior of the inhabitants of the local island communities and lower levels of economic development. A similar attitude of men and women concerning the development of sustainable tourism offers can be an advantage and boost gender-sensitive policy of entrepreneurship and employment in the tourism sector.

Partially confirmed Hypothesis 2 showed a more significant difference in the positive attitudes of the middle-aged group, which indicates the need for careful marketing communication in relation to other age groups, especially concerning certain aspects of sustainable tourism (cruising, cultural tourism, rural tourism). It is possible that the benefits of developing sustainable tourism are not visible to the younger and older population.

Confirming the Hypothesis 3 has highlighted the clearer perception of local residents who are employed in the tourism sector about the advantages and disadvantages of tourism development, which is consistent with the results of other studies (Inbakaran, Jackson, 2005) and indicates the need for greater sensitivity tourism policy holder in relation to groups of residents working in other sectors. Residents employed in other sectors can have a negative attitude towards the development of tourism offers if they see them as a threat to their own business or their employment identity (Nunkoo, Gursoy, 2OI2), which should be taken into account in the process of marketing planning.

The Hypothesis 4 regarding significant monitoring of the developments in the tourism market of highly educated residents and resident-employees in the tourism sector, public services, culture and education in relation to other comparable groups has been confirmed 
which is similar to the results of other studies (Inbakaran, Jackson, 2005) and indicates significantly higher degree of marketing awareness. Other groups of local people possibly need sales and marketing training.

The rejection of the Hypothesis 5 shows that the place of residence does not significantly affect the views of local residents about the development of sustainable tourism offers which is a different result compared to the aforementioned study (Inbakaran, Jackson, 2005) which has observed that the inhabitants of distant places of tourist attractions have a more positive attitude related to tourism. It is an interesting result because it is an area of clear multiculturalism in terms of the different ethnic and religious composition of the local population (Montenegrins, Bosniaks, Albanians), which probably does not significantly affect the views on tourism, although some studies (Uriely, Israeli and Reichel, 2003) show the inhabitants of a religious groups provide less support for the development of cultural heritage tourism of other religious groups support or provide support conditional of the positive affirmation of their own religious and cultural heritage.

The following discussion will present segments of marketing planning that are directly related to the local population and are directly dependent on the expressed positive and negative attitudes of some groups of local residents.

Relevant to the situation analysis is the fact that the local population, in general, understand the importance and expresses mainly mid-level of satisfaction with the development of some forms of sustainable tourism.

However, some groups, such as residents of middle-aged, well-educated citizens and residents employed in the tourism sector have significantly clear differences, which suggests that it is necessary to examine their importance in the decision-making process and the potential for conflict situations.

Clear differences affect the formation of the mission, vision and goals of the area as an important stage of marketing planning.

It is necessary to formulate a mission through the following statements concerning the local population:

- Encouraging investment in carriers of the offers of sustainable forms of tourism

- Increase the accountability of harmonious social and cultural development while preserving the environment

Clearly, population groups, such as residents of young and old age, residents of other educational levels and employees in other sectors will not express positive or negative attitudes about investing in certain types of sustainable tourism in the same way. The mission could be supplemented by additional position of importance to local residents:

- Promotion of the concept of harmonizing the interests of the local community regarding the development of sustainable tourism offers

Careful attention should be given to profiling of the segment vision as a time-dimensioned expectation in 2020 , in terms of the local community:

Carefully chosen locations already and spatially harmonized accommodation and other tourist facilities in function of the realization of a wider range of tourism offers to a number of spending groups of tourists. A supportive social environment for the development of new tourist products is of greatest interest to the local population.

Key marketing aims of the Skadar Lake area as realistically achievable and measurable conditions of importance to the local community in the longer term to $202 \mathrm{O}$ are: 
I. Improving the level of awareness of the local population in terms of the benefits the development of sustainable forms of tourism, especially in the identified group;

2. Increasing support for the development through development of positive and reduction of negative attitudes to sustainable tourism offers;

3. Achieving the optimum rate of profitability on sustainable tourism principles

This raises the crucial question of the level of commitment and involvement of local people in relation to the local community as the basis for the differential response of certain groups. The results of other studies suggest that the level of commitment and involvement can only be clearly linked to the perceived benefits (Lee, 20I3) but not the costs of the development of sustainable tourism, which would mean that the groups of Skadar Lake area residents who express more positive attitudes may have a greater degree of commitment and involvement due to a clearer perception of the benefits. It is possible to say that groups which have less positive attitudes expressed more fear of the negative effects of tourism development in relation to the benefits.

These claims should be investigated by future research.

Formulation and implementation of marketing strategies, the design of partial and integral tourism product, design and implementation of the activities of the promoting mix, price formation and policies of sales channels and control of the implementation of marketing plans as well as other segments of the marketing planning may be to some extent realized under more or less influence by the attitudes of local residents.

It is important to note several aspects of the above effects.

Important definition of the success of the development of partial tourism products is the level of understanding, interest and support of the local population.

Integrated tourism product of the "Skadar Lake" area must have a clear, distinctive identity as a new, highly diverse in content, nature and cultural heritage oriented product within the general product range from Montenegro.

The objectives of the promotional policy in the long term, among others, are:

- Increasing the level of understanding and support of the local population for development initiatives;

- Establishment of an integrated system of communication at all levels of decision-making significance in the destination

Pricing policies and sales channels need to be carefully formulated taking into account the particular interests of local residents in terms of efficiency of product placement and optimization of profit margins.

Good institutional structure of the marketing management of the area of Skadar Lake will enable effective control and optimal operation of all stakeholders of the supply of forms of sustainable tourism.

Marketing planning of the offers of sustainable tourism must be based on the desired relation to meeting the needs of tourism consumers and meeting the basic interests of the local population in the protected areas.

The key issue is to find an institutional approach in the community that ensures a more comprehensive marketing plan. 


\section{References}

Arnstein, S.R. (I969). A ladder of citizen participation. Journal of the American Institute of Planners, 35 (4), 2I6-224; in: Lee, H.T. 2OI3. Influence analysis of community resident support for sustainable tourism development. Tourism Management, 34, 37-46.

Biddle, B.J., Bank, B.J. and Slavings, R.L. (1987). Norms, preferences, identities and retention decesions. Sociological Psychology Quarterly, 50, 322-337; in Nunkoo, R. and Gursoy, D. 2OI2. Residents' Support for Tourism, An Identity Perspective. Annals of Tourism Research, 39 (I), 243-268.

Blay P. (I964). Exchange and power in social life, John Wiley, New York; in: Uriely, N., Israeli, A. and Reichel, A. 2003. Religious Identity And Residents' Attitudes Toward Heritage Tourism Development: The Case of Nazareth. Journal of Hospitality \& Tourism Research, 27 (I), 69-84.

Buttler, R. (I980). The concept of tourist area cycle of evolution: Implications for management of resources. Canadian Geographer, 24, 5-I2; in: Uriely, N., Israeli, A. and Reichel, A. 2003. Religious Identity And Residents' Attitudes Toward Heritage Tourism Development: The Case of Nazareth. Journal of Hospitality \& Tourism Research, 27 (I), 69-84.

Doxy, G. (1975). A causation theory of visitor-resident irritants: Methodology and research inferences. In Travel and Toursim Research Association, sixth annual proceedings, University of Utah, Salt Lake City, I95-I98; in: Uriely, N., Israeli, A. and Reichel, A. 2003. Religious Identity And Residents' Attitudes Toward Heritage Tourism Development: The Case of Nazareth. Journal of Hospitality \& Tourism Research, 27 (I), 69-84.

Durkheim, E. ([19I5] I995). The Elementary Forms of the Religious Life, Free Press, New York; in: Woosnam, M.K. and Norman, C.W. 2OIO. Measuring Residents' Emotional Solidarity with Tourists: Scale Development of Durkheim's Theoretical Constructs. Journal of Travel Research, 49 (3), 365-380.

Gursoy, D., Chi, C.G. and Dyer, P. (2009). An examination of locals' attitudes. Annals of Tourism Research, 36, 723-726; in Lee, H.T. 20I3. Influence analysis of community resident support for sustainable tourism development. Tourism Management, 34, 37-46.

Hagger, M.S., et al. (2007). Aspects of identity and their influence of intention behavior: Comparing effects for three health behaviors. Personality and Individual Difference, 42, 355-367; in Nunkoo, R. and Gursoy, D. 2012. Residents' Support for Tourism, An Identity Perspective. Annals of Tourism Research, 39 (I), 243-268.

Haralambopoulos, N. and Pizam, A. (1996). Perceived impact of tourism: The case of Samos. Annals of Tourism Research, 23 (3), 503-526; in: Uriely, N., Israeli, A. and Reichel, A. 2003. Religious Identity And Residents' Attitudes Toward Heritage Tourism Development: The Case of Nazareth. Journal of Hospitality \& Tourism Research, 27 (I), 69-84.

Harrill, R. (2004). Residents' Attitudes toward Tourism Development: A literature Review with Implications for Tourism Planning. Journal of Planning Literature, I8 (3), 25I-266; in: Woosnam, M.K. and Norman, C.W. 2OIO. Measuring Residents' Emotional Solidarity with Tourists: Scale Development of Durkheim's Theoretical Constructs. Journal of Travel Research, 49 (3), 365-380.

Homans, G. (1967). The nature of social science, Harcourt Brace and World, New York; in: Uriely, N., Israeli, A. and Reichel, A. 2003. Religious Identity And Residents' Attitudes Toward Heritage Tourism Development: The Case of Nazareth. Journal of Hospitality \& Tourism Research, 27 (I), 69-84. 
Inbakaran, R. and Jackson, R. (2005). Marketing regional tourism: How better to target and address community attitudes to tourism. Journal of Vacation Marketing, II (4), 323-339.

Jamal, T. and Getz, D. (I995), Collaboration theory and community tourism planning. Annals of Tourism Research, 22, I83-2O2; in: Lee, H.T. 2OI3. Influence analysis of community resident support for sustainable tourism development. Tourism Management, 34, 37-46.

Job, H. and Paesler, F. (2OI3). Links between nature-based tourism, protected areas, poverty alleviation and crises - The example of Wasini Island (Kenya). Journal of Outdoor Recreation and Tourism, I-2, I8-28.

Lai, P.H. and Nepal, S.K. (2006). Local perspectives of ecotourism development in Tawushan Nature Reserve, Taiwan. Tourism Management, 27 (6), III7-II29; in: Lee, H.T. 2OI3. Influence analysis of community resident support for sustainable tourism development. Tourism Management, 34, 37-46.

Lee, H.T. (2OI3). Influence analysis of community resident support for sustainable tourism development. Tourism Management, 34, 37-46.

McCool, S.F. and Martin, S.R. (I994). Community attachment and attitudes toward tourism development. Journal of Travel Research, 32 (3), 29-34; in: Lee, H.T. 2OI3. Influence analysis of community resident support for sustainable tourism development. Tourism Management, 34, 37-46.

Nicholas, L., Thapa, B. and Ko, Y. (2009). Resident's perspectives of a world heritage site the Pitons Management Area, St. Lucia. Annals of Tourism Research, 36 (3), 390-4I2; in: Lee, H.T. 2OI3. Influence analysis of community resident support for sustainable tourism development. Tourism Management, 34, 37-46.

Nunkoo, R. and Gursoy, D. (2OI2). Residents' Support for Tourism, An Identity Perspective. Annals of Tourism Research, 39 (I), 243-268.

Okazaki, E. (2008). A community-based tourism model: its conception and use. Journal of Sustainable Tourism, I6 (5), 5II-529; in: Lee, H.T. 2OI3. Influence analysis of community resident support for sustainable tourism development. Tourism Management, 34, 37-46.

Palm, P. and Pye, O. (2OOI). The potential of community base tourism and the role of development cooperation in Namibia. Begleitprogramm Tropenökologie der GTZ, Publication no. TOB F-V/I2e. Eschborn; Job, H. and Paesler, F. 2OI3. Links between nature-based tourism, protected areas, poverty alleviation and crises - The example of Wasini Island (Kenya). Journal of Outdoor Recreation and Tourism, I-2, I8-28.

Pearce, P.L., Moscardo, G. and Ross, G.F. (1996). Tourism Community Relationships, Elsevier, Oxford, UK; in: Woosnam, M.K. and Norman, C.W. 2OIO. Measuring Residents' Emotional Solidarity with Tourists: Scale Development of Durkheim's Theoretical Constructs. Journal of Travel Research, 49 (3), 365-380.

Pennington-Gray, L. (2005). Residetn attitudes towards tourism in a destination in the stagnation stage of the tourism life cycle. Sustainable Development and Planning, 2, I4II-I4I8; in: Lee, H.T. (2OI3). Influence analysis of community resident support for sustainable tourism development. Tourism Management, 34, 37-46.

Sebele, L.S. (2OIO). Community-based tourism ventures, benefits and challenges: Khama Rhino Sanctary Trust, Central District, Botswana. Tourism Management, 3I, I36-I46; in Lee, H.T. 2OI3. Influence analysis of community resident support for sustainable tourism development. Tourism Management, 34, 37-46.

Selin, S. and Chaves, D. (1995). Developing a collaborative model for environmental planning and management. Environmental Management, 9, I89-I95; in Lee, H.T. 2013. 
Influence analysis of community resident support for sustainable tourism development. Tourism Management, 34, 37-46.

Skidmore, W. (1975). Theoretical thinking in sociology, Cambridge University, London; in: Nunkoo, R. and Gursoy, D. 2OI2. Residents' Support for Tourism, An Identity Perspective. Annals of Tourism Research, 39 (I), 243-268.

Stets, J.E. and Biga, C.F. (2003). Bringing identity theory into environmental sociology. Sociological Theory, 2I, 398-423; in: Nunkoo, R. and Gursoy, D. 2OI2. Residents' Support for Tourism, An Identity Perspective. Annals of Tourism Research, 39 (I), 243-268.

Taylor, G. (1995). The community approach: does it really work? Tourism Management, I6 (7), 487-489; in Lee, H.T. 2OI3. Influence analysis of community resident support for sustainable tourism development. Tourism Management, 34, 37-46.

Tosun, C. (2006). Expected nature of community participation in tourism development. Tourism Management, 27, 493-504; in: Lee, H.T. 2OI3. Influence analysis of community resident support for sustainable tourism development. Tourism Management, 34, 37-46.

Uriely, N., Israeli, A. and Reichel, A. (2003). Religious Identity And Residents' Attitudes Toward Heritage Tourism Development: The Case of Nazareth. Journal of Hospitality \& Tourism Research, 27 (I), 69-84.

Woosnam, M.K. and Norman, C.W. (2OIO). Measuring Residents' Emotional Solidarity with Tourists: Scale Development of Durkheim's Theoretical Constructs. Journal of Travel Research, 49 (3), 365-380. 